\title{
CLOUD Profit or Loss : Google as Case
}

\author{
Rana M. Faek \\ College of Computer Science \\ and Engineering \\ Educational Institution \\ Hail, Kingdom of Saudi \\ Arabia
}

\author{
AfraaSayahAlshammari \\ College of Computer Science \\ and Engineering \\ Educational Institution \\ Hail, Kingdom of Saudi Arabia
}

\author{
Dr. KusumYadav \\ College of Computer Science \\ and Engineering \\ Educational Institution \\ Hail, Kingdom of Saudi \\ Arabia \\ Kusumasyadav0@gmail.com
}

\author{
EbtisamA. Hamed \\ College of Computer \\ Science and Engineering \\ Educational Institution \\ Hail, Kingdom of Saudi \\ Arabia
}

\begin{abstract}
-
In recent times the cloud storage usage has is tremendously proved its significance in almost every discipline from knowledge, sciences and technology and education or business and management and the list continues. the impact, usefulness and usability of different applications in in different sector affecting the technical sector positively. In this paper we are discussing the pros and cons of cloud storage usage among Arab users and the awareness of its security threats which will shed a further step to examining cloud computing and evaluate its evolvements. The research survey was conducted in different countries of middle east mainly Kingdom of Saudi Arabia (KSA), Palestine and Jordan.
\end{abstract}

Keywords-; Google Cloud, CloudStorage, Cloud Computing, Cloud Security.

\section{INTRODUCTION}

Google cloud storage usage is tremendously increasing in almost every discipline from sciences such as the resent study in 2016 by H. S. Moat et alas they conclude the contribution on the value of search engine data as a new data resource for cognitive scientists and providing a new tool to help them in understanding the human decision [1]. Also, in the education sector such as the study done by Brown and Hocutt in 2015 as the examined the student of the first year college in their composition course perceptions on the usefulness and usability of Google Apps for Education (GAFE) which resulted in an overall relatively easy opinion from the students and concluded on (GAFE) as a helpful tool to achieve the course learning objectives [2]. Business and technology is another sector that Google cloud is impacting tremendously according to Newstex Global Business Blogs last year where Cisco predicted that cloud-based IP traffic willboost up four times in the next five years [3].And so on many other disciplines is effected by cloud computing and highlighting a late study in 2010 by N. Sultan [4], as he predicted on the popularity that cloud computing will receive in future years with some risks mention but few, will the future is here and the popularity of cloud computing services are supported from the above mansions.

This growth had lead to increase in the cloud storage market to reach US\$25.171 billionlast year(2017) and expected to reach US $\$ 92.488$ billion in 2022. An important factor that contributed in this massive growth was due to Google successful promotion to businesses and governmental agencies that are already seeking for alternative cheap ways such as cloud computing [5].
Along with great advantages of using cloud storage, risks and threats are unfortunately associated with it are very alerting especiallywhen it comes to security issues. Furthermore, each day, a fresh news item, blog entry, or other publication warns us about cloud computing security [6]. In most cases, security is cited as the most substantial roadblock for cloud computing uptake [7]. Cloud computing can help protecting data of private people and in particular can help companies accomplish more by breaking the physical bonds between an IT infrastructure and its users [8].

One of the important issues for any person is the security of his information and the trust in the system that deals with it. In addition, in our days it is almost impossible to find a single person in the developed countries who is not exchanging and storing information via the Internet. Google cloud platform is a pioneer in today's information technology such as its searching engine [9].

In this research a light will be shed byexploring the depth of Google cloud usage among Arab users and the awareness of its security threats which will shed a further step to examining cloud computing and evaluate its evolvements. Three Arab countries participated in this research, which are the Kingdom of Saudi Arabia (KSA), Palestine and Jordan.

\section{RESERCH METHEDOLGY}

A. Methadolgy

This study was conducted in April, 2018with 79 participants from Hail city in KSA, Palestine and Jordan. The data was collected by using an online survey. The questionnaire questions were designed to comprise five sections which are: 
- User background in using cloud-based data storage.

- Generate statistics on Google drive usage.

- Statistical data on the user's knowledge of the disadvantages of cloud-based data storage.

\section{B. Participants}

The participants in this study considered the socity in general, as this stydy do not target a specific group of people.

\section{RESULTS AND DISCUSSION}

79 responces were collected through the survayfrom KSA, Palestine and Jordan. The ratio of responces for each of the threecountries are provided in Table 1 below.

\begin{tabular}{|l|c|}
\hline \multicolumn{1}{|c|}{ Participants } & Responses Ratio \\
\hline KSA & $65.82 \%$ \\
\hline Palestine & $15.2 \%$ \\
\hline Jordan & $18.98 \%$ \\
\hline
\end{tabular}

\section{Table 1: The Ratio of Responses from Participants}

The first section of the questionnaire, 85.5\%responded with yes as shown in Figure 1 below. This finding indemnifies Google drive popularity among Arab users.

\section{?Do you have an account on Google - 1}

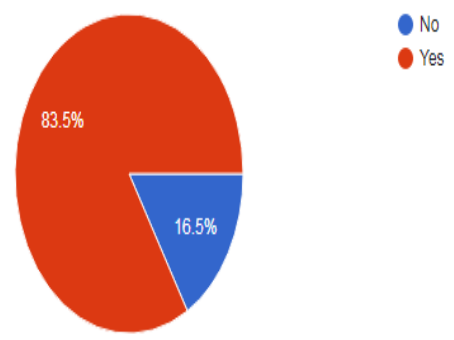

\section{Figure 1.Acquiring Google Account}

Next question was to evaluate the users opinion on the protection feature of Google and the results insures the users believe with $79.7 \%$ responded with yes which agreed with whatGoogle platform implies [9].Figure 2 below illustrates this question below.

\section{2- Do you think it offers you protection for your information?}

\section{9 responses}

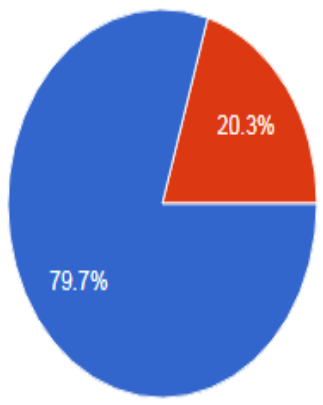

Figure 2.Protoction of the Google Cloud

The next two questions asked on any file losing incidents the users may had facedand are they using their Google account for important files. The first question resulted in $79.9 \%$ no indicating positive responds for the protection feature of Google. While the other question resulted in $58.2 \%$ yes showing that over half of the users use their Google account in important file whether they were work or personal files. This also, indicates that a more advertising on the features of using Google account in critical aspect of users is needed. The results of the two questions are provided in Figure 3 and 4 respectively.

The third section of the survey was conducted to gainstatistical data on already owning educational cloud data storage by asking the participants with a simple yes/no question that yields to a $59 \%$ with negative responses as illustrated in Figure 3.

\section{3- Have you lost some of your files in your Google account?}

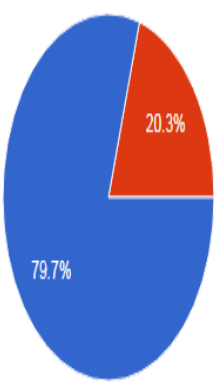

No

$$
\text { Yes }
$$

Figure 3.Lossing File Incidents in Google Account 


\section{4-Have you used a Google account to store important informati} 79 responses

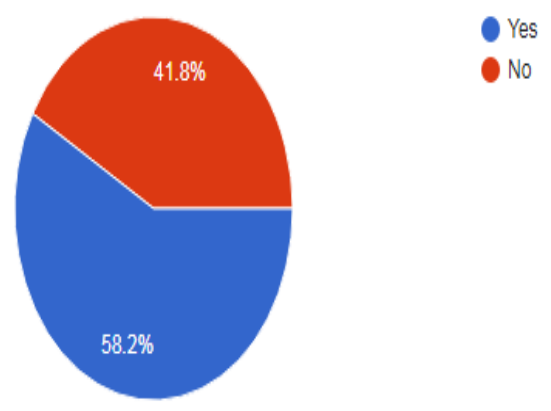

Figure 4.Using Google Account for Important Files

Figure 5below shows $86.1 \%$ of the participants responded negatively on any hacking incidents that they may have faced. Furthermore, the last two questions ask the users if they feel safe and their privacy is secure and the findings were $78.5 \%$ and $62 \%$ as shown in Figure 6 and 7 respectively.

\section{5-Have you ever your account hacked?}

79 responses

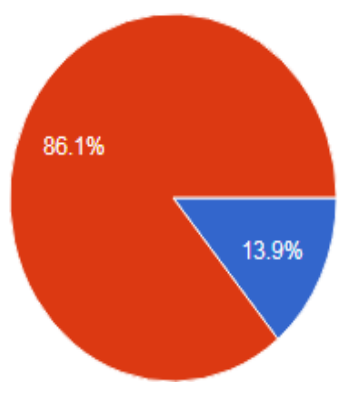

Figure 5.Hacking Incidents in Google Account 6-Do you think Google is safe?

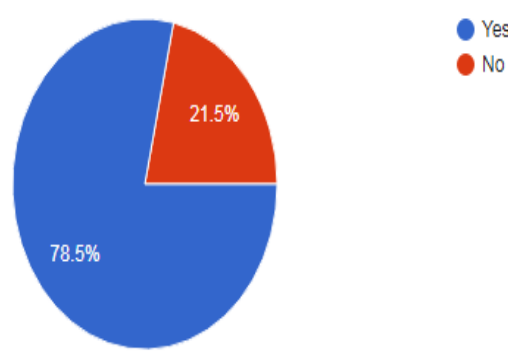

Figure 6.Saifty of Google Account

\section{Do you feel private when you save your data in a Google Account?}

79 responses

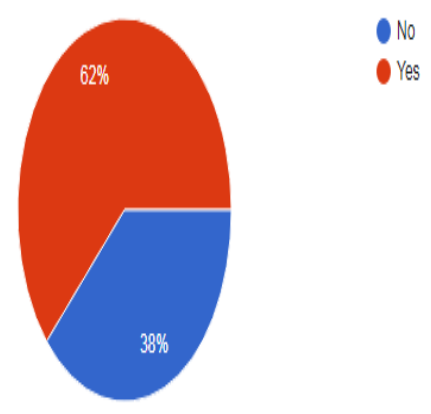

Figure 7.Privecy of Google Account

\section{CONCLUSION}

This research shares different aspects of using cloud storage and also, unfortunately the risks and threats involved and associated with it In this research is clear that Arab users are trusting Google as the main concern for its security threats still exists. We can say that the user's percentage is not high.

\section{FutURE SCOPE}

Security is every individual's responsibility and hence requires lots of constant and continuous monitoring to ensure that all good and ethical practices will be aligned to keep the business compliant on cloud. The future of cloud security will rely on intelligent automation based on best and ethical practices and cyber regulations led up by the government. According to the interest for wellbeing arrangements out in the open and private associations, human services organizations, internet business, protection, and saving money segments has been continually expanding because of expanding scenes occurrence of digital assaults. Extensive scale endeavors has effectively received the cloud security administrations inferable from visit assaults on server farms. Little and medium scale undertakings are assessed to indicate significant development at a CAGR $35.1 \%$ over the conjecture time frame as there is expanded consciousness of security dangers.

\section{REFERENCES}

[1] H. S. Moat et al, "Searching Choices: Quantifying Decision-Making Processes Using Search Engine Data," Topics in Cognitive Science, vol. 8, (3), pp. 685-696, 2016.

[2]Brown, M. and Hocutt, D. (2018). Learning to Use, Useful for Learning: A Usability Study of Google Apps for 
EducationJUS. [online] Uxpajournal.org. Available at: http://uxpajournal.org/usability-study-google-appseducation/ [Accessed 26 Aug. 2018].

[3] Anonymous "The Hindu Business Line: Google Cloud meet begins," Newstex Global Business Blogs, 2017.

[4] N. Sultan, "Cloud computing for education: A new dawn?" International Journal of Information Management, vol. 30, (2), pp. 109-116, 2010.

[5]https://www.businesswire.com/news/home/20170614005 856/en/92.48

[[7]http://misprivate.boun.edu.tr/kutlu/mis492/CloudSecurit y.pdf)

[8] Ransome, John W.(2017)Cloud computing :

implementation, management, and security. Available at :

(http://cutt.us/H4tW1)

[9] Source:google cloud platform(2017).Google Security Whitepaper.:(https://cloud.google.com/security/whitepaper). 